\title{
Diabetes Drug Therapy - First Do No Harm
}

\author{
Frederic R. Curtiss, PhD, RPh, CEBS, and Kathleen A. Fairman, MA
}

I n the November/December 2006 issue of JMCP, Watkins et al. reported the estimated value of exenatide in treating obese patients with type 2 diabetes over a 30-year time horizon, as calculated using the Center for Outcomes Research Diabetic Model, a validated Markov model that predicts clinical and economic end points over time horizons up to 100 years in duration. ${ }^{1}$ Adopting the premise that "sophisticated disease-based economic models can be substituted" when "long-term outcomes data are lacking," the authors sought to provide guidance to managed care organizations making formulary decisions about new products. In fact, development of the model, a collaborative effort between exenatide's manufacturer and a 1.6 million member health plan with an active formulary review process, began several months before approval of the product by the U.S. Food and Drug Administration (FDA). The model's findings for exenatide, including incremental cost-effectiveness ratios of $\$ 13,000$ per quality-adjusted life-year compared with insulin and $\$ 32,000$ compared with generic glyburide, were used as a basis for the health plan's decision to cover exenatide after a step-therapy trial of metformin.

Two key assumptions used in this pharmacoeconomic analysis are noteworthy. First was an assumed $8.5 \%$ (about $15-20$ pound) weight loss associated with exenatide treatment in a hypothetical patient population with mean body mass index (ratio of weight in kilograms to height in meters squared $\left[\mathrm{kg} / \mathrm{m}^{2}\right]$ ) of $35 \mathrm{~kg}$ per $\mathrm{m}^{2}$, assumed to result in mean reductions of $10 \mathrm{~mm} \mathrm{Hg}$ in systolic blood pressure, $20 \mathrm{mg}$ per $\mathrm{dL}$ in low-density lipoprotein cholesterol, $59 \mathrm{mg}$ per dL in triglycerides, and corresponding reductions in medical costs to treat cardiovascular events. These assumptions were extrapolated liberally from the approximate $3 \%$ weight loss observed in the 30-week clinical trials that were cited in the product label and the approximate 5\% weight loss observed in the open-label follow-up for 314 (57.0\%) of 551 subjects randomized to exenatide who completed 82 weeks of therapy. Second and more important, the study by Watkins et al. failed to include the cost to treat adverse drug events in the pharmacoeconomic model, in effect assuming that these were $\$ 0$ or equal across treatment arms, but did acknowledge that more patients discontinued therapy with exenatide compared with placebo.

As often happens with pharmacoeconomic modeling performed early in a product's history, the actual data from realworld use ultimately do not support and potentially could even contradict the model assumptions. ${ }^{2}$ Absent evidence to support the assumption of sustained weight loss with exenatide or what this weight loss might mean in actual cardiovascular event risk reduction, validation of this key assumption is currently an empirical question. Notably, the model's assumption regarding the unimportance of adverse events was quickly found to be fundamentally flawed. Less than a year after the study by Watkins et al. was published, the FDA announced that it had reviewed 30 cases of acute pancreatitis associated with the use of exenatide $^{3}$ and announced that the manufacturer had agreed to "update Byetta's label to discuss pancreatitis." Ten months later on August 18, 2008, the FDA updated its warning regarding acute pancreatitis with a notice to health care professionals that 6 cases involved hemorrhagic or necrotizing pancreatitis, all 6 cases required hospitalization, and 2 patients died. ${ }^{5}$ The upgraded warning includes a contraindication for the use of exenatide in patients with a history of pancreatitis. This example highlights one of the shortcomings of pharmacoeconomic modeling for new drugs - that efficacy outcomes are more likely to be known than are adverse effects for drugs that are new to market.

In this issue of JMCP, Asche and Nelson comment on a previous review by VanDeKoppel et al. of the place in therapy of 3 new agents for diabetes: exenatide, pramlintide, and sitagliptin. ${ }^{6}$ Asche and Nelson call for research with administrative claims and other post-marketing surveillance to help better define the safety and effectiveness of these new diabetes drugs. ${ }^{7}$ However, there is already quite a bit known about the adverse effects associated with these drugs, particularly sitagliptin and exenatide.

Valdez in her commentary in this issue of JMCP expresses hope for the superiority of newer diabetes agents in providing some advantage over existing agents, ${ }^{8}$ certainly a need given the explosion in the number of cases of type 2 diabetes in the United States and worldwide. ${ }^{9}$ However, there is only limited evidence, primarily from animal models, of some potential value of the dipeptidyl peptidase-4 (DPP-4) inhibitors in possibly preserving beta-cell function, the foundation for the hope expressed by Valdez in her commentary.

Both Valdez, and Ashe and Nelson, acknowledge the recent (April 2008) Cochrane Systematic Review of DPP-4 inhibitors in their commentaries but stop short of informing us of the substance of this systematic review of 25 studies. This Cochrane Systematic Review (CD006739) included only randomized controlled trials (RCTs) of at least 12 weeks duration for adult patients with type 2 diabetes. ${ }^{10}$ From 1,083 publications regarding DPP-4 
inhibitors, 52 were evaluated in detail and 25 of these were rejected as reviews or overviews. Of the 25 studies (reported in 27 publications) that met the inclusion criteria, 11 RCTs involved a total of 6,743 patients randomized to sitagliptin and 14 RCTs involved 6,121 patients randomized to vildagliptin, a drug not yet approved by the FDA. This 134-page systematic review showed that sitagliptin and vildagliptin in meta-analysis of the combined clinical trial results had modest effects on Alc $(-0.7 \%$ for sitagliptin and $-0.6 \%$ for vildagliptin). Adverse event outcomes showed a significantly higher incidence of all-cause infections with sitagliptin and a possibly higher incidence with vildagliptin, but comparison with placebo was not statistically significant for vildagliptin. Since the DPP-4 inhibitors may affect immune function, the 2008 Cochrane Review called for additional data on the long-term safety of these drugs.

Letters posted on the FDA website last year mentioned "hypersensitivity post-marketing adverse reaction data," and the label for Januvia (sitagliptin) was revised in October 2007 to include in the "Warnings and Precautions" section the following additional wording, "There have been postmarketing reports of serious allergic and hypersensitivity reactions in patients treated with Januvia such as anaphylaxis, angioedema, and exfoliative skin conditions including Stevens-Johnson syndrome."11 Dermatologic reactions may be characteristic of the class of DPP-4 drugs since the use of vildagliptin (Galvus) in monkeys has been associated with dermatologic reactions that have reportedly kept vildagliptin off the U.S. market, and in November 2007, dose-related elevations in liver enzymes were discovered with vildagliptin $100 \mathrm{mg}$ once daily, making entry to the U.S. market more unlikely. ${ }^{12}$

The Cochrane Review published in April 2008 was preceded by a systematic review and meta-analysis (Amori et al.) in July 2007 of the safety and efficacy of incretin therapy, ${ }^{13}$ which encompasses glucagonlike peptide 1 (GLP-1) drugs such as exenatide that mimic incretin, and the DPP-4 inhibitors such as sitagliptin that enhance the effect of incretin. This earlier review included many of the RCTs of the DPP-4 inhibitors that were evaluated in the Cochrane Review that followed in 2008. However, Amori et al. noted an unexplained increased risk of headache with DPP-4 inhibitors and put some context around the concern about the possible adverse effect on immune function - patients with diabetes are more likely to develop urinary tract infections (UTIs) and are at a higher risk of complications, including death from urosepsis. Amori et al. used the example of a seemingly small relative risk of 1.52 for UTIs, which in their estimate potentially increases the number of UTIs by 1 million new cases per year in a population of 20 million persons with type 2 diabetes.

For the GLP-1 drugs, Amori et al. reported that nausea was the most common side effect, and 4\% of clinical trial patients who received exenatide withdrew because of nausea and vomiting. Zinman et al. (2007) found in a 16-week trial of add-on therapy (added to thiazolinedione [TZD] with or without metformin) that $16 \%$ of the patients who received exenatide versus $2 \%$ who received placebo did not complete the clinical trial because of adverse events; $40 \%$ of exenatide patients versus $15 \%$ of placebo patients experienced nausea, and $13 \%$ of exenatide patients versus $1 \%$ of placebo patients experienced vomiting. ${ }^{14}$ Also, despite only 16 weeks duration, 29\% of the exenatide patients and 14\% of placebo patients did not complete the study.

Nathan et al. in the 2008 Consensus Algorithm from the American Diabetes Association and the European Association for the Study of Diabetes find no place in therapy for pramlintide, exenatide or sitagliptin in patients with type 2 diabetes. ${ }^{15}$ Separately, Nathan criticized the FDA for approving sitagliptin despite the "paucity of published data from long-term clinical trials."16 The evidence of the risk of adverse events with new GLP-1 and DPP-4 antidiabetic drug therapies combined with 5 risk-warning events in 2007 for the 2 TZDs (rosiglitazone and pioglitazone $)^{17}$ and the absence of conclusive evidence of reduction in macrovascular risk with any of the FDA- approved drugs for type 2 diabetes, ${ }^{18}$ provide more context for the recommendation by the FDA outside expert panel in July this year to require more evidence than Alc reduction for FDA approval of new drug applications for antidiabetic therapies. ${ }^{19,20}$ More evidence of the safety of new drugs for type 2 diabetes is sorely needed.

\section{Authors}

FREDERIC R. CURTISS, PhD, RPh, CEBS, is Editor-in-Chief of the Journal of Managed Care Pharmacy. KATHLEEN A. FAIRMAN, MA is Associate Editor and Senior Methodology Reviewer of the Journal of Managed Care Pharmacy.

AUTHOR CORRESPONDENCE: Frederic R. Curtiss, PhD, RPh, CEBS, Academy of Managed Care Pharmacy, 100 North Pitt St., Suite 400, Alexandria, VA 22314. Tel.: 830.935.4319; E-mail:fcurtiss@ amcp.org

\section{DISCLOSURES}

The authors report no conflicts of interest related to the subjects or products discussed in this article.

\section{REFERENCES}

1. Watkins JB, Minshall ME, Sullivan SD. Application of economic analyses in U.S. managed care formulary decisions: a private payer's experience. J Manag Care Pharm. 2006;12(9):726-35. Available at: www.amcp.org/data/ jmcp/726-735.pdf.

2. Fairman KA, Curtiss FR. It's only a pharmacoeconomic model—believe it or not. J Manag Care Pharm. 2007;14(1):83-85. Available at: www.amcp. org/data/jmcp/JMCPMaga_JanFeb\%2008_083-085.pdf.

3. U.S. Food and Drug Administration. Information for healthcare professionals - exenatide (marketed as Byetta). October 16, 2007. Available at: www.fda.gov/CDER/drug/InfoSheets/HCP/exenatideHCP.htm. Accessed August 20, 2008.

4. Anonymous. FDA says diabetes drug may cause pancreatitis. Wall Street J. Oct 17, 2007:B15. 
5. U.S. Food and Drug Administration. Information for healthcare professionals - exenatide (marketed as Byetta). Updated August 18, 2008. Available at: www.fda.gov/CDER/drug/InfoSheets/HCP/exenatide2008HCP.htm. Accessed August 22, 2008.

6. VanDeKoppel S, Choe HM, Sweet BV. Managed care perspective on three new agents for type 2 diabetes. J Manag Care Pharm. 2008;14(4):363-80. Available at: www.amcp.org/data/jmcp/JMCPMaga_363-380.pdf.

7. Asche C, Nelson R. The benefits and risks of new therapies for type 2 diabetes. J Manag Care Pharm. 2008;14(7):655-657.

8. Valdez CA. New agents in the management of type 2 diabetes: do they provide an opportunity for a shift in the treatment paradigm? J Manag Care Pharm. 2008;14(7):650-654

9. International Diabetes Federation. Diabetes prevalence. Available at: www.idf.org/home/index.cfm?node=264. Accessed August 24, 2008 .

10. Richter B, Bandeira-Echtler E, Bergerhoff K, Lerch CL. Dipeptidyl peptidase-4 (DPP-4) inhibitors for type 2 diabetes mellitus. Cochrane Database Syst Rev. 2008(2):CD006739.

11. U.S. Food and Drug Administration—safety labeling changes approved by the FDA Center for Drug Evaluation and Research (CDER) - October 2007. Available at: www.fda.gov/Medwatch/safety/2007/oct07.htm. Accessed August 24, 2008

12. Reuters News Service. Novartis diabetes drug delayed - liver-safety worry slows drug's path to Europe market. Wall Street J. Nov 7, 2007:D8.

13. Amori RE, Lau J, Pittas AG. Efficacy and safety of incretin therapy in type 2 diabetes. JAMA. 2007;298(2):194-206. Available at: www.jama.amaassn.org/cgi/content/full/298/2/194. Accessed August 24, 2008.

14. Zinman B, Hoogwerf BJ, Garcia SD, et al. The effect of adding exenatide to a thiazolidinedione in suboptimally controlled type 2 diabetes. Ann Intern Med. 2007;146(7):477-85. Available at: www.annals.org/cgi/ reprint/146/7/477.pdf. Accessed August 24, 2008.
15. Nathan DM, Buse JB, Davidson MB, et al. Management of hyperglycemia in type 2 diabetes: a consensus algorithm for the initiation and adjustment of therapy. Diabetes Care. 2008; 31(1):173-75. Available at: www.care.diabetesjournals.org/cgi/reprint/31/1/173. Accessed August 24, 2008.

16. Nathan DM. Finding new treatments for diabetes-how many, how fast... how good? N Engl J Med. 2008;356(3):437-40.

17. Starner CI, Schafer JA, Heaton AH, Gleason PP. Rosiglitazone and pioglitazone utilization from January 2007 through May 2008 associated with five risk-warning events. J Manag Care Pharm. 2008;14(6):523-31. Available at: www.amcp.org/data/jmcp/JMCPMaga_523-531.pdf.

18. Joffe HV. Cardiovascular assessment in the pre-approval and postapproval settings for drugs and biologics developed for the treatment of type 2 diabetes mellitus. Presentation to the FDA Endocrinologic and Metabolic Drugs Advisory Committee, July 1-2, 2008. Available at: www.fda.gov/ ohrms/dockets/ac/08/slides/2008-4368sl-08-FDA-Joffe.ppt. Accessed August 24, 2008.

19. U.S. Food and Drug Administration. Center for Drug Evaluation and Research. Background introductory memorandum. The role of cardiovascular assessment in the pre-approval and post-approval settings for drugs and biologics developed for the treatment of type 2 diabetes mellitus. Guidance for industry: diabetes mellitus: developing drugs and therapeutic biologics for treatment and prevention. February 13, 2008. Available at: www.fda.gov/ cder/guidance/7630dft.htm. Accessed August 24, 2008.

20. Anonymous. FDA panel calls for more testing of diabetes drugs. Medline Plus. July 3, 2008. Available at: www.nlm.nih.gov/medlineplus/news/fullstory_66518.html. Accessed August 25, 2008. 